\title{
Article \\ A Source of Systematic Errors in the Determination of Critical Micelle Concentration and Micellization Enthalpy by Graphical Methods in Isothermal Titration Calorimetry
}

\author{
Mónica Corea ${ }^{1}$, Rogelio Jiménez-Juárez ${ }^{2}$, Gabriela Martínez-Mejía ${ }^{2} \mathbb{D}$, María de Jesús Martínez-Ortiz ${ }^{1} \mathbb{D}$ \\ and José Manuel del Río ${ }^{3, *(D)}$
}

1 Programa de Nanociencias y Micro-Nanotecnologías, Instituto Politécnico Nacional, Escuela Superior de Ingeniería e Industrias Extractivas, UPALM, Edificio Z-5 PB, San Pedro Zacatenco, Del. Gustavo A. Madero, C.P. 07738 Ciudad de Mexico, Mexico; mcoreat@yahoo.com.mx (M.C.); mjmartinez@ipn.mx (M.d.J.M.-O.)

2 Departamento de Química Orgánica, Instituto Politécnico Nacional, Escuela Nacional de Ciencias Biológicas, Prolongación de Cárpio y Plan de Ayala s/n Miguel Hidalgo, C.P. 11340 Ciudad de Mexico, Mexico; rjimenezg@ipn.mx (R.J.-J.); gmmejia@outlook.es (G.M.-M.)

3 Laboratorio de Investigación en Polímeros y Nanomateriales, Instituto Politécnico Nacional, Escuela Superior de Ingeniería Química e Industrias Extractivas, UPALM, Edificio Z-5 PB, San Pedro Zacatenco, Del. Gustavo A. Madero, C.P. 07738 Ciudad de Mexico, Mexico

* Correspondence: jm.delrio.garcia@gmail.com

\section{check for}

updates

Citation: Corea, M.; Jiménez-Juárez, R.; Martínez-Mejía, G.;

Martínez-Ortiz, M.d.J.; del Río, J.M. A

Source of Systematic Errors in the

Determination of Critical Micelle

Concentration and Micellization Enthalpy by Graphical Methods in Isothermal Titration Calorimetry. Entropy 2021, 23, 236. https:// doi.org/10.3390/e23020236

Academic Editor: Jean-Noël Jaubert

Received: 19 January 2021

Accepted: 6 February 2021

Published: 18 February 2021

Publisher's Note: MDPI stays neutral with regard to jurisdictional claims in published maps and institutional affiliations.

Copyright: (c) 2021 by the authors. Licensee MDPI, Basel, Switzerland. This article is an open access article distributed under the terms and conditions of the Creative Commons Attribution (CC BY) license (https:// creativecommons.org/licenses/by/ $4.0 /)$.

\begin{abstract}
Isothermal titration calorimetry is frequently employed to determine the critical micelle concentration and the micellization enthalpy of surfactants in terms of geometrical characteristics of the titration curves. Previously we have shown theoretically that even for an infinitesimal injection, the heat per titrant mol depends on the stock solution concentration. In this work, we explore experimentally the influence of the stock solution concentration on the geometrical characteristics of the titration curve and its effect in determining the critical micelle concentration and the micellization enthalpy of surfactants. The systematic study of this phenomenology involves a great number of measurements at different temperatures with several repetitions carried out using a robotic calorimeter. As surfactant hexadecyltrimethylamonium bromide was used. The magnitude and shape of the heat titration depend on the stock solution concentration. As a consequence, the inflexionpoint, break-point, and step-height decrease until a limiting value. A qualitative analysis suggests that the limiting value depends only on substance. This work shows that graphical methods could not be suitable for the calculation of the critical micelle concentration and micellization enthalpy because the magnitude and shape of the titration curve depend on the stock solution concentration. Micellar properties should be calculated by the application of theoretical models as in the ligandbinding studies.
\end{abstract}

Keywords: isothermal titration calorimetry; critical micelle concentration; micellization enthalpy; micelle formation

\section{Introduction}

Isothermal titration calorimetry is an experimental technique which measures the heat involved in a titration process [1,2]. Basically, an isothermal titration calorimeter consists of a syringe which contains a titrant and a cell (surrounded by calorimetric detectors) which contains the titrated liquid. A quasi-isothermal condition [3] is achieved by compensating electrically the heat flow absorbed or released from each titration process. The first isothermal titration calorimeters [1,2] were developed to study chemical reactions. Other applications such as macromolecular binding [1,2], liquid mixtures [1,4,5] and micelle formation [1,2] were also developed. In this work, we are interested in the application of isothermal titration calorimetry to the study of micelle formation thermodynamics. 
The experiment of micelle formation, such as we know (see Figure 1), was originally proposed by Olofsson [6-8] who built the first titration curves for micelle formation and provided a phenomenological interpretation which is still employed nowadays. This interpretation is based upon the idea that changes in the titration curve reflect changes in the aggregation state. Recently some authors have given experimental evidence about this relation by fluorescence [9], small-angle neutron scattering [10], small-angle X-ray scattering [10], scanning transmission electron microscopy [10] as well as Monte Carlo simulation [10]. Olofsson also proposed a method calculating the enthalpy of micelle formation $\left(\Delta_{\text {mic }} h\right)$ and a method to obtain a value of the critical micelle concentration $(C M C)$.

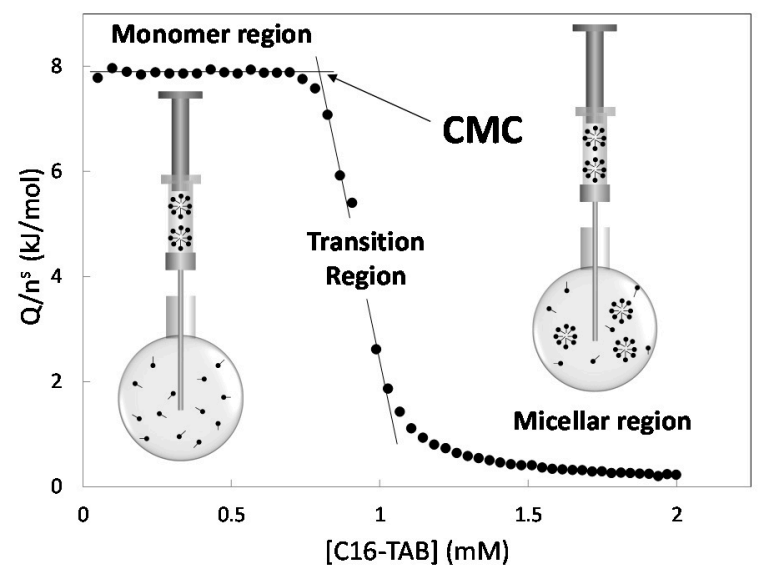

Figure 1. Titration curve at $25^{\circ} \mathrm{C}$ obtained in this work using hexadecyltrimethylammonium bromide (C16-TAB) as surfactant. In this type of curve, the titration heat per unit titrant mol is represented against the titrant concentration in the cell. The stock solution concentration in the syringe was $5.0 \mathrm{mM}$. In this case the critical micelle concentration is around $1 \mathrm{mM}$. A criterion to obtain the critical micelle concentration $(C M C)$ is in terms of the point where the monomer region breaks down $[6,7,11,12]$.

Van Os and coworkers [13] using an automatic isothermal titration calorimeter, proposed other methods for calculating $\Delta_{\text {mic }} h$ and the $C M C$. Both methods were derived from other experimental techniques. The graphical method for obtaining $\Delta_{\text {mic }} h$ was taken from that developed by the group of Desnoyers $[14,15]$ for Picker calorimeters $[16,17]$ and is based upon the following Equation (see Appendix A for details):

$$
L_{2}^{a}-L_{2}^{b}=\Delta_{m i c} h+\left(m-m_{C M C}\right)\left(\frac{\partial \Delta_{m i c} h}{\partial m}\right)
$$

where $L^{a}{ }_{2}$ and $L^{b}{ }_{2}$ are the linear extrapolations from the micellar region and from the monomer region, respectively, and $\mathrm{m}$ is the concentration on the molality scale. In order to get $\Delta_{\text {mic }} h$ by Equation (1), the extrapolated values $L^{a}{ }_{2}$ and $L^{b}{ }_{2}$ must be evaluated at the $C M C$. Because a value of the $C M C$ is required, van Os and coworkers developed a criterion to determine it which was adapted from techniques such as electrical conductivity [18], sound speed [19], or surface tension [20]. In this method, the CMC is calculated from the intercept of the linear extrapolations from the monomer and micellar regions in the cumulated heat of titration. This method has been used by many other authors [21-23]. In addition, Equation (1) established the "standard method" used hereafter in the bibliography: the enthalpy of micelle formation is obtained by the difference between the linear extrapolations from the monomer and micellar regions evaluated at the CMC.

In 1995, Paula and coworkers [24] proposed another method for calculating the $C M C$ by isothermal titration calorimetry. These authors observed that the minimum (or maximum) of the first derivative of the titrant heat per titrant $\mathrm{mol}\left(\mathrm{Q} / \mathrm{n}^{\mathrm{s}}\right)$ with respect to the concentration is in the transition region between monomer and micellar regions, and for this reason, they proposed this point as $C M C$. 
In 1998, Kresheck [25] proposed using an empirical fit function to obtain the CMC as the inflexion point of the titrant heat per titrant mol. Other improvements of this method were proposed by Király and Dekány [26] and by Textor and Keller [27].

Isothermal titration calorimetry is a recent and widely used technique which provides a relatively quick determination of the CMC and $\Delta_{\text {mic }} h$ with a good degree of accuracy [28]. For this reason, it is interesting to study in detail Equation (1) which is the thermodynamic foundation of the "standard method." Appendix A shows that $L_{2}$ in Equation (1) is calculated by a partial derivative of the Euler Equation for the relative enthalpy $L$ of the system without applying the corresponding Gibbs-Duhem Equation to cancel null terms. The reorganization of these null terms in Equation (1) gives the artificial term $(C M C-m)\left(\partial \Delta_{m i c} h / \partial m\right)$ which is also null. For this reason, the correct form of Equation (1) is:

$$
L_{2}^{a}-L_{2}^{b}=\Delta_{m i c} h
$$

Equation (2) is not suitable for graphical evaluation because if the monomer and micellar region are not flat, the difference $L_{2}^{a}-L_{2}^{b}$ will depend on the concentration and $\Delta_{\text {mic }} h$ will be undetermined. In addition, it is not possible to directly apply Equation (1) to isothermal titration calorimeters because the titration heat per titrant mole is not always the partial relative enthalpy of the solute $[1,2]$. This is only true when the titrant is a pure liquid compound $[1,2,4,5]$.

On the other hand, an argument in favor of the standard method has been proposed by some authors $[25,29]$. In these works, the CMC was obtained in terms of inflexion points and $\Delta_{\text {mic }} h$ was obtained by means of the difference between the extrapolations at the CMC. To probe the thermodynamic consistency, they used the van't Hoff Equation to predict the $C M C$ from $\Delta H_{\mathrm{m}}$ and $\triangle C p_{\mathrm{m}}$ obtaining agreement within the experimental error. This result suggests that certain geometrical characteristics of the titration heat curves could be considered as reasonable approximations of micellar properties. Our problem now is to determine whether the geometrical characteristics of the titration curves depend only on the substance or also on the experimental design of the titration process.

From a theoretical approach, it is possible to see qualitatively if the stock solution concentration can affect the titration curve. By notation, in the work we will use the subindex C16-TAB to refer to the total complex solute (surfactant). This complex solute is composed by surfactant in monomer state and surfactant in micellar estate. In the case of a 2-component system, the solvent will be component 1 and the solute will be component 2 . Considering a 2-component system without reaction or aggregation, the titration heat per titrant mole in an infinitesimal titration is [1,2]:

$$
\frac{d Q}{d n_{2}^{s}}=\frac{\rho_{2}^{s}-c_{2}^{s}}{c_{2}^{S}} h_{1 ; 2}\left(c_{2}\right)+h_{2 ; 1}\left(c_{2}\right)-\frac{1}{c_{2}^{s}} h_{v}\left(c_{2}^{S}\right)
$$

where components 1 and 2 are respectively the solvent and solute, $c_{2}$ and $c^{s}{ }_{2}$ are respectively the concentration of solute in the titration cell and in the stock solution, $h_{1 ; 2}$ and $h_{2 ; 1}$ are respectively the molar enthalpy of 1 and 2 and $h_{v}\left(c^{s}{ }_{2}\right)$ is the enthalpy per unit volume of the stock solution. The stock solution concentration in Equation (3) could affect the titration curve by a vertical shift by means of the term $\left(1 / c^{\mathcal{S}}{ }_{2}\right) h_{v}\left(c^{\mathcal{S}}{ }_{2}\right)$. In addition, it could affect the shape of the titration curve. The relative titration heat is defined as:

$$
\frac{d Q_{L}}{d n_{2}^{s}}=\frac{d Q}{d n_{2}^{s}}-\left(\frac{d Q}{d n_{2}^{s}}\right)^{0}
$$

where the extrapolated value $\left(d Q / d n^{s}\right)^{0}$ is defined as:

$$
\left(\frac{d Q}{d n^{s}}\right)^{0} \equiv \lim _{\mathcal{C}_{2} \rightarrow 0} \frac{d Q}{d n^{s}}
$$


Substituting (3) and (5) in Equation (4) the relative titration heat can be written as:

$$
\frac{d Q_{L}}{d n_{2}^{s}}=\frac{\rho_{2}^{s}-c_{2}^{\mathcal{S}}}{c_{2}^{S}} l_{1 ; 2}\left(c_{2}\right)+l_{2 ; 1}\left(c_{2}\right)
$$

where $l_{1 ; 2}$ and $l_{2 ; 1}$ are the relative partial enthalpies [30] of the components 1 and 2 respectively, which depend only on the substance. From Equation (6), the shape of the relative titration heat curve could be affected by the stock solution concentration by means of the term $\left(\rho^{s}{ }_{2}-c^{s}{ }_{2}\right) / c^{s}{ }_{2}$. That is, even for a simple model of a 2-component system without reaction or aggregation, the value of the stock solution concentration can change the magnitude and shape of the heat titration curve.

As it was said, the titration curve shape is related to structural changes in micellar aggregates $[9,10]$. On the other hand, different theoretical approaches of the titration heat, in terms of the apparent molar heat [31,32], or in terms of infinitesimal titrations [1,2], indicate the dependence of the titration heat curve on stock solution concentration. To clarify how the stock solution concentration affects the geometrical properties of the titration curves, we have systematically scanned the proposed phenomenology using a robotic calorimeter. With this instrument we can change the stock solution concentration within an appropriate experimental range, repeating each titration curve four times at different temperatures to determine the effect on $\Delta_{m i c} C p$. All titration curves have been measured in the same range of concentration (independently of the stock solution concentration) and all curves had a minimum amount of points before (and after) CMC. This study provides experimental evidence about the effect of the stock solution concentration on the break-point, the inflexion point, and the height of the step of the heat titration curves.

\section{Material and Methods}

Because the number of runs is large, we selected an inexpensive surfactant with a low CMC (1 mM): hexadecyltrimethylammonium bromide (C16-TAB; Fluka > 99\%). The water was twice distilled and then deionized using a MicroPure ST Barnstead purification system from ThermoScientific.

The calorimeter was an Automated MicroCal PEAQ-ITC from Malvern Panalytical (Northampton, MA, USA). The sample cell is coin-shaped with a volume of 200 microliters and the titration syringe has a volume of 40 microliters. The level noise in the thermogram is around $0.63 \mathrm{nW}$ and the temperature stability at $25^{\circ} \mathrm{C}$ is around $\pm 0.00012{ }^{\circ} \mathrm{C}$. This robotic instrument is equipped with a sample tray containing four sample plates each with 48 sample wells. One robotic arm controls and cleans the titration syringe and another two robotic arms clean the sample cell and take the samples from the sample tray to use them in the cell and in the syringe. This instrument can work continuously without supervision following a preset work program.

To check the effect of the stock solution on the titration curve six stock solution concentrations were prepared from $5 \mathrm{mM}$ to $40 \mathrm{mM}$ in flasks of $100 \mathrm{~mL}$ (see Table 1).

Table 1. Parametrization of runs with different stock solution concentrations. The CMC of C16-TAB is about $1 \mathrm{mM}[23,33-37]$ and all titration curves were measured in the interval of concentration from 0 to $3 \mathrm{mM}$ of $\mathrm{C} 16-\mathrm{TAB}$.

\begin{tabular}{cccccc}
\hline $\begin{array}{c}\text { Stock } \\
\text { Solution } \\
\text { Number }\end{array}$ & $\begin{array}{c}\text { Stock Solution } \\
\text { Concentration } \\
(\mathbf{m M})\end{array}$ & $\begin{array}{c}\text { Titration } \\
\text { Volume }(\boldsymbol{\mu L})\end{array}$ & $\begin{array}{c}\text { Injection } \\
\text { Duration (s) }\end{array}$ & $\begin{array}{c}\text { Number of } \\
\text { Sub-Runs }\end{array}$ & $\begin{array}{c}\text { Number of } \\
\text { Titrations Per } \\
\text { Subrun }\end{array}$ \\
\hline 1 & 5.0 & 2.00 & 3.00 & 5 & 19 \\
2 & 10.0 & 1.00 & 2.00 & 2 & 39 \\
3 & 15.0 & 0.67 & 1.34 & 2 & 39 \\
4 & 20.0 & 0.50 & 1.00 & 1 & 70 \\
5 & 25.0 & 0.37 & 0.74 & 1 & 68 \\
6 & 30.0 & 0.31 & 0.62 & 1 & 60 \\
\hline
\end{tabular}


The measurement of a titration curve was considered as a run. For low stock solution concentrations, the titration volume is relatively large and so we carried out a small number of titrations with a completely full syringe. In these cases, the run had to be split into several sub-runs. Between sub-runs, the robotic system subtracted an amount of liquid from the cell and refilled the syringe. Sub-run thermograms were merged using the Malvern Panalytical software MicroCal Concat ITC (version 1.0). Table 1 shows the experimental parameters of the runs. All titration curves were measured from 0 to $3 \mathrm{mM}$. For this reason, when the stock solution concentration changed, all experimental parameters must also vary (see Table 1) to avoid undesirable side effects and to take advantage of the instrument robotization. For example, if the titration volume and the number of titrations are constant while the stock solution varies, the concentration interval of the titration curves will differ, producing systematic errors in the data processing. In the same way, if the concentration interval and the titration volume are held constant, the number of titrations will change dramatically, again generating systematic errors in the data processing. As a criterion, a reasonable variation in the number of titrations per run was allowed while ensuring the monomer region contained at least 10 points.

To take advantage of the robotization, the number of repetitions for each stock solution concentration and temperature was kept at four to provide an additional source of precision. A water-water test was interspersed every two repetitions to check the correct performance of the equipment. The heat registered in these water-water runs is produced by the friction of the fluid in the syringe needle [2]. For each temperature, the total number of sub-runs, including the water-water test, was 72, and the total number of sub-runs in this work was 216. The time duration of a water-water test including the cleaning of the cell and the syringe is around $2 \mathrm{~h}$, while the duration of a sub-run depends on the number and duration of the titrations. The total time to complete a work program was around one and half weeks, which required the robotic calorimeter to work continuously.

The data processing was carried out with methods implemented by algorithms. This automatization of the calculus also avoids the bias introduced by the subjectivity, experience and/or appreciation of the operator in the application of the methods. In this work, the break-point of the monomer region and the inflexion point of the titration curve will be calculated as measurements of the CMC. As a measure of the micellization enthalpy, we will calculate the high step of the titration curve at the CMC. All methods were programed in Excel spreadsheets.

In the break-point method (Figure 2A), the titration curve was divided into three regions. Regions 1 and 3 were defined in terms of empirical fit functions, and region 2 was considered as a transition region. In the first region, the titration heat per mole of titrant was constant in all measured titration curves. The following criterion was employed to define this region. Initially, the group of the first six points was taken. A new point was included in the group if it lay within the interval $\left[\mathrm{x}_{\mathrm{A}}-3 \sigma, \mathrm{x}_{\mathrm{A}}+3 \sigma\right]$ where $\mathrm{x}_{\mathrm{A}}$ and $\sigma$ are the average and standard deviation of the new group and so on. This method stops when the new point does not fall in the interval $\left[\mathrm{x}_{\mathrm{A}}-3 \sigma, \mathrm{x}_{\mathrm{A}}+3 \sigma\right]$ indicating the end of the monomer region. The points of region 3 were fitted to the empirical function:

$$
f(x)=\frac{A}{x-B}+C
$$

where $A, B$ and $C$ are parameters which were obtained minimizing the function:

$$
\chi^{2}=\sum_{i}\left[y_{i}-f\left(x_{i}\right)\right]^{2}
$$



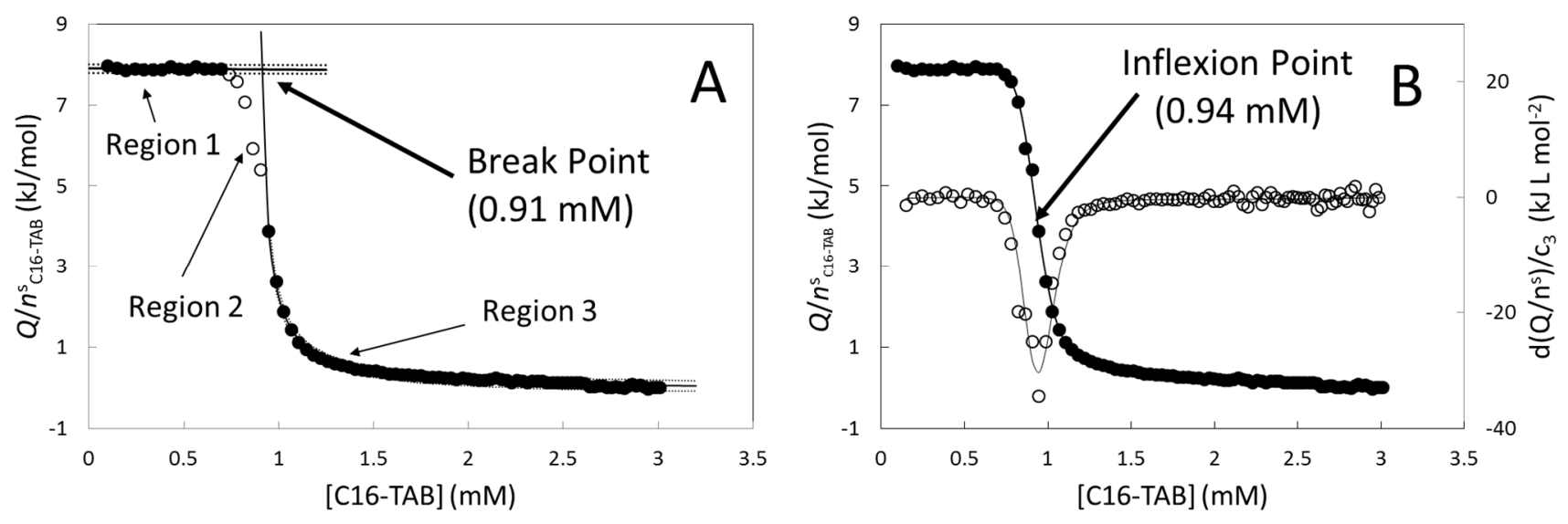

Figure 2. (A) break-point method and (B) inflexion point method employed to determine the CMC. The titration curve of both (A) and (B) is the same as in Figure 1. Filled circles in (A) represent the points included in the monomer and micellar regions. In (B) open circles represent the first derivative calculated using a centered finite differences scheme.

This calculation was carried out using the SOLVER of Excel with the following parametrization. The method in the minimization was the GRG Nonlinear, the precision restriction was $1 \times 10^{-250}$ and the scheme of derivatives was central. The micellar region was defined in the same way as the monomer region. After the fit of the function (7) to the six latest points, the following point is included in the region if it is within the interval of three standard deviations around the value $f(x)$. The standard deviation [38] was estimated according to the following Equation:

$$
\sigma^{2} \approx \frac{1}{m-n} \sum_{i=1}^{n}\left[y_{i}-f\left(x_{i}\right)\right]^{2}
$$

where $m$ is the number of parameters of the fit function (in this case 3), and $n$ is the number of points. The following points were included following the same criterion. The $C M C$ was calculated by the intercept of the constant value of the first region and the function $f(x)$ of the third region (see Figure 2A). Comparing Figures 1 and 2A, the proposed method yields values of the break-point bigger than that of Figure 1 using two straight lines. Other differences are that the method implemented by two straight lines depends on the number and position of the points of the transition region and on the subjective appreciation of the operator to define the transition region. The proposed method does not depend on these characteristics and as consequence is numerically more stable and easier to program.

The inflexion point method was implemented in the following way. Figure $2 \mathrm{~B}$ shows the first derivative of the titration curve with respect to the concentration of C16-TAB. The shape of this experimental first derivative was described in this work as an asymmetric Gaussian function:

$$
g(x)=A \exp \left\{-\left(\frac{x-C M C}{\sigma_{0}+\sigma_{1} x+\sigma_{2} x^{2}+\sigma_{3} x^{3}}\right)^{2}\right\}
$$

where $\sigma_{0}, \sigma_{1}, \sigma_{2}, \sigma_{3}$, and $C M C$ are fit parameters. In this way, the experimental points of the titration curve will be fitted to the empirical function:

$$
f(x)=\int_{0}^{x} g\left(x^{\prime}\right) d x^{\prime}+\sigma_{4}
$$

where $\sigma_{4}$ is the other fit parameter. All fit parameters of Equations (10) and (11) were calculated by minimizing the function $\chi^{2}$ of Equation (8) using the SOLVER of Excel and the integral of Equation (11) was calculated numerically using the rectangle rule. 
The parameter $C M C$ in Equation (10) plays the role of a minimum implying that it takes the role of an inflexion point in Equation (11).

The high step of the titration curves, as a measure of $\Delta_{\text {mic }} h$, was calculated using the method proposed by van Os [13] evaluated at the break-point and at the inflexion point (Figure 3). The linear regions were defined in a similar criterion of the three standard deviations around the fit as in the break-point method.

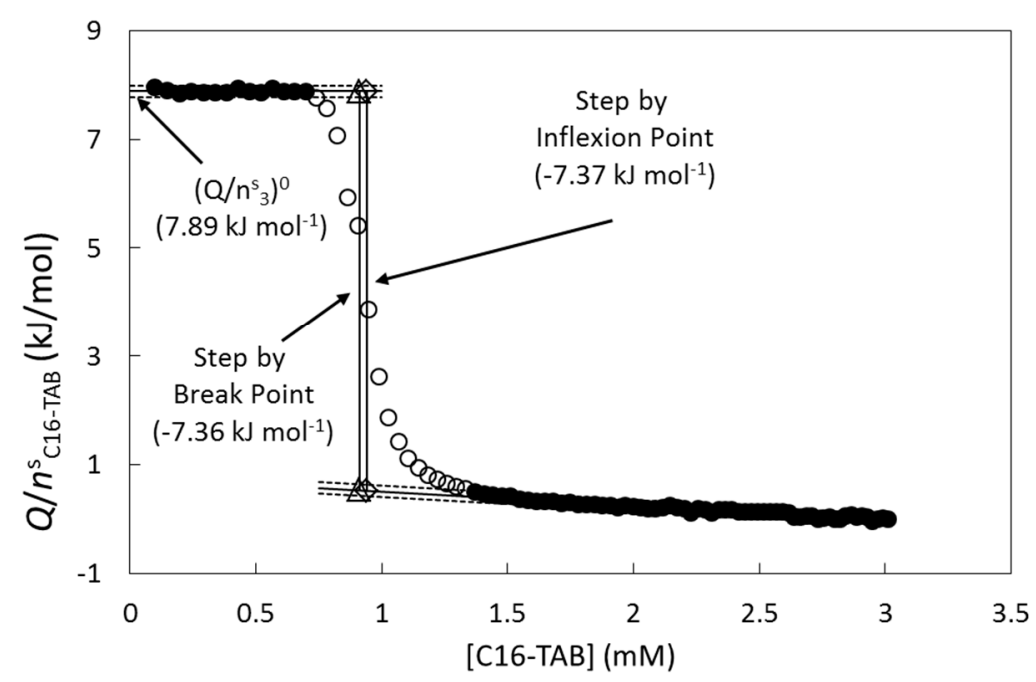

Figure 3. Graphical methods used to calculate the step height of the titration curve. The filled circles are the points included in the linear fits; points not included are open circles. The titration curve was the same as in Figure 1.

Another thermodynamic property calculated from the titration curves was the extrapolated value $\left(Q / n^{s} \text { C16-TAB }\right)^{0}$ obtained by Equation (5) using the linear fit of the first region (Figure 3).

\section{Result and Discussion}

Figure 4 shows the averaged titration curves at $25^{\circ} \mathrm{C}$ (Figure $4 \mathrm{~A}$ ), $35^{\circ} \mathrm{C}$ (Figure $4 \mathrm{~B}$ ), and $45^{\circ} \mathrm{C}$ (Figure $4 \mathrm{C}$ ). At all temperatures, the height of the monomer and micellar regions increases with the stock solution concentration. Because this increment is bigger in the monomer region than in the micellar region, it is clear that the step height (a measure of $\Delta_{\text {mic }} h$ ) is affected by the stock solution concentration. In addition to this, it is clear in Figure 4 that the length of the monomer region (a measure of the $C M C$ ) decreases with the stock solution concentration.

It is usual to measure the titration curve at different temperatures to study the effect of the temperature on the $C M C$ and on $\Delta_{\text {mic }} h[24-26,29,37]$. The heat capacity of micellization is obtained by plots of the enthalpy of micellization against the temperature. These studies were carried out preparing only one stock solution. Figure 5 shows two examples of the effect of temperature on the titration curve for two different stock solution concentrations indicating clearly the dependence of this type of study on the stock solution concentration. The arbitrariness is evident because the step height at $45^{\circ} \mathrm{C}$ for the stock solution concentration of $5.0 \mathrm{mM}$ is similar to the step height at $35^{\circ} \mathrm{C}$ for the stock solution concentration of $25.0 \mathrm{mM}$.

Figure 6 shows the effect of the stock solution concentration on the extrapolated value defined in Equation (5). The extrapolated value depends linearly on the temperature in the temperature interval studied (see Figure 6A) while the slope of the linear fits depends on the stock solution concentration. It is interesting to observe that the extrapolated value for $5.0 \mathrm{mM}$ at $35{ }^{\circ} \mathrm{C}$ is practically the same as the value for $25.0 \mathrm{mM}$ at $25{ }^{\circ} \mathrm{C}$. Figure $6 \mathrm{~B}$ shows the extrapolated value as function of the stock solution concentration at 
several temperatures. In all cases, the extrapolated value increases with the stock solution concentration up to a limiting value.
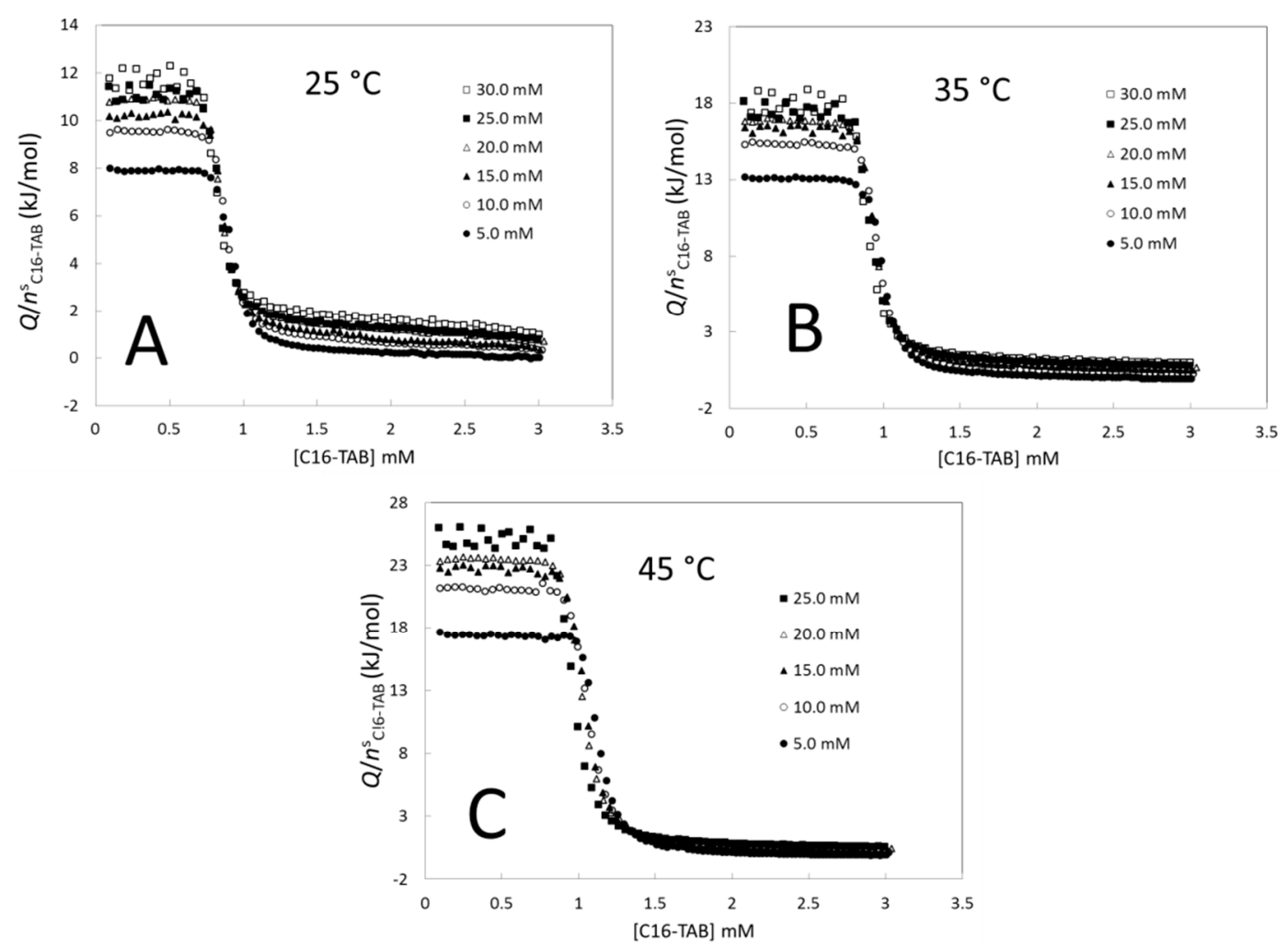

Figure 4. Averaged titration curves of $\mathrm{C} 16-\mathrm{TAB}$ at different stock solution concentrations and temperatures.
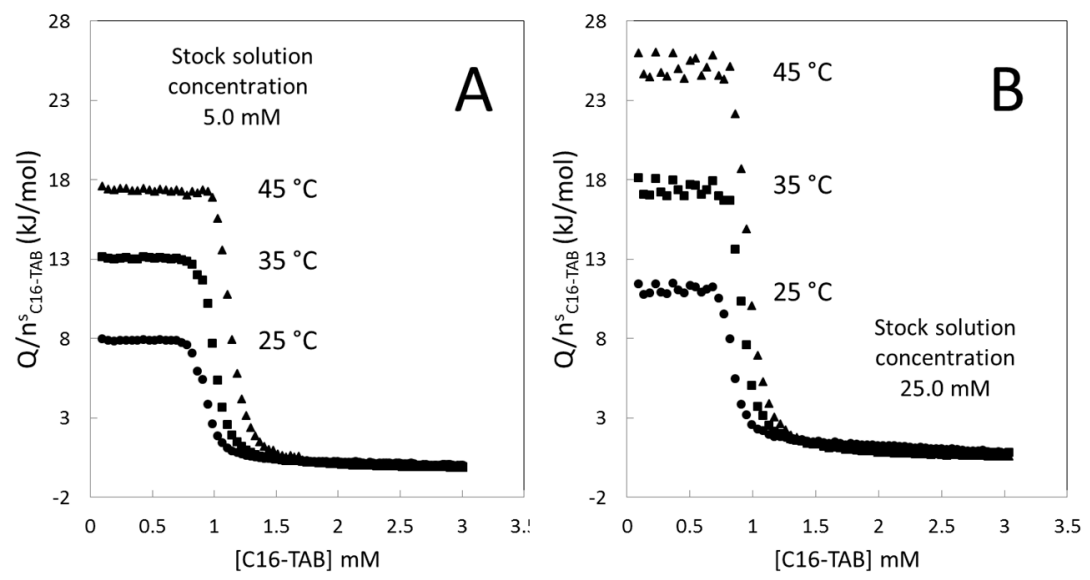

Figure 5. Heat titration curves of $\mathrm{C} 16-\mathrm{TAB}$ at different temperatures for two stock solution concentrations using data of Figure 4. (A) the stock solution concentration is $5.0 \mathrm{mM}$ and (B) the stock solution concentration is $25.0 \mathrm{mM}$. This Figure shows how it would be the results of two different authors using two different stock solution concentrations in the same study of micellization of C16-TAB. 

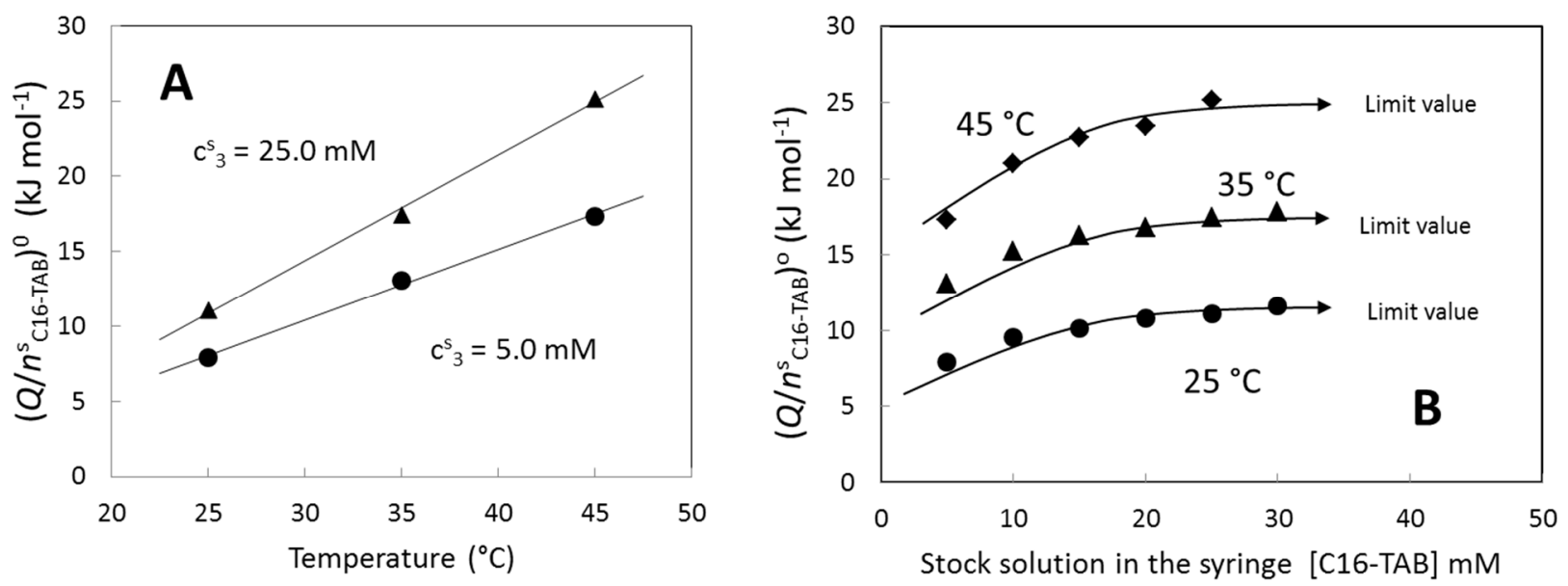

Figure 6. (A) Extrapolated value (see Equation (5)) of C16-TAB as function of the temperature for two stock solution concentrations. (B) Extrapolated value of C16-TAB as function of the stock solution concentration at several temperatures.

Figure 7 shows the break-points and inflexion points calculated from the titration curves of Figure 4. The results from these two methods are similar. Figure 7A shows the break-points and inflexion points as a function of the temperature for two different stock solution concentrations. The arbitrariness of these values as function of the temperature is evident (see Figure 7A) because the values for $5.0 \mathrm{mM}$ at $25^{\circ} \mathrm{C}$ are similar to the values for $25.0 \mathrm{mM}$ at $35^{\circ} \mathrm{C}$. Figure $7 \mathrm{~B}$ shows the break-points and inflexion points with respect to the stock solution concentration at different temperatures. In all cases, the values decrease with the stock solution concentration until a limiting value. This result is consistent with the length reduction of the first plateau in the titration curves in Figure 4 when the stock solution concentration increases. Although it is usual that the authors do not report the exact concentration of the stock solution, it is interesting to analyze the inflexion point results of this work in the context of the literature data. Figure 8A shows the inflexion point data for 5.0, 25.0, and $30.0 \mathrm{mM}$ and data of $C M C$ from the bibliography (Table S1 in Supporting Material). All bibliography data were obtained by isothermal titration calorimetry using an inflexion-point method of a break-point method [23,28,33-37]. Except for one point that clearly falls out of the general trend, all the literature data are between the values measured with the stock solution concentrations of $5.0 \mathrm{mM}$ and $30.0 \mathrm{mM}$, indicating that the effect of the stock solution concentration on the inflexion point explains the scattering of the CMC literature data for the C16-TAB.
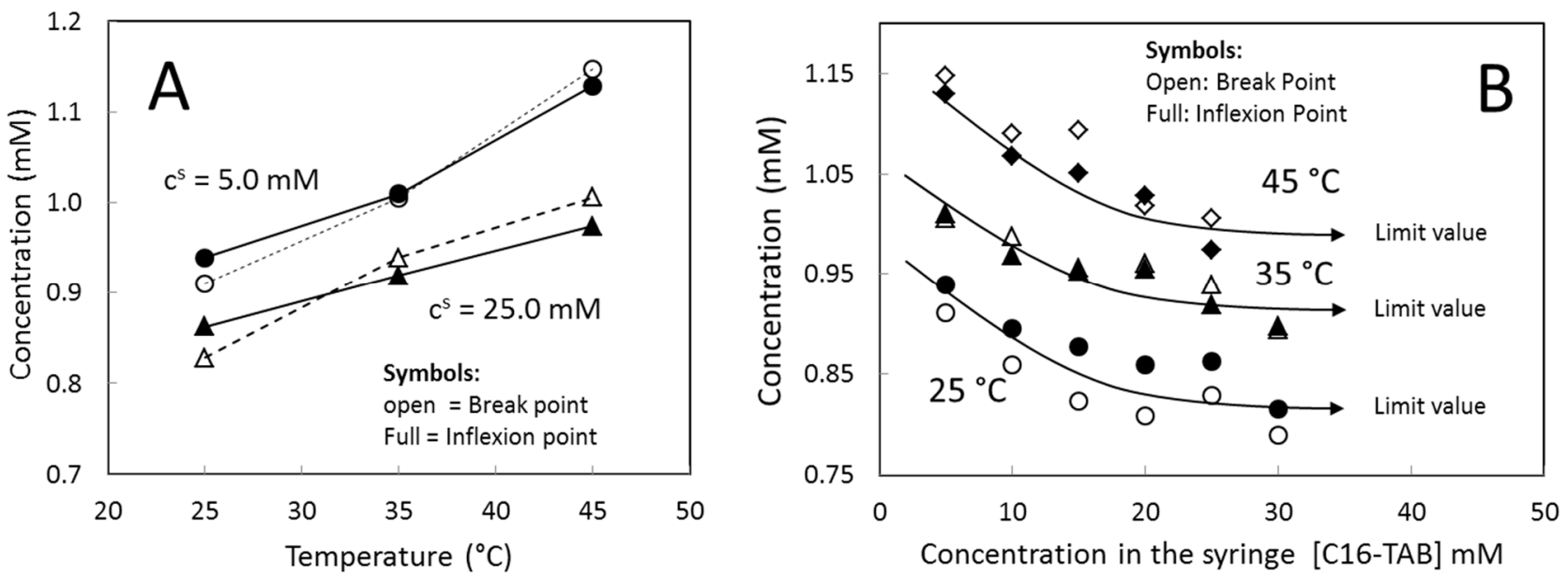

Figure 7. (A) Inflexion-point (full symbols) and break-point (open symbols) as function of the temperature for two stock solution concentrations. (B) Inflexion-point (full symbols) and break-point (open symbols) as function of the stock solution concentration at several temperatures. 

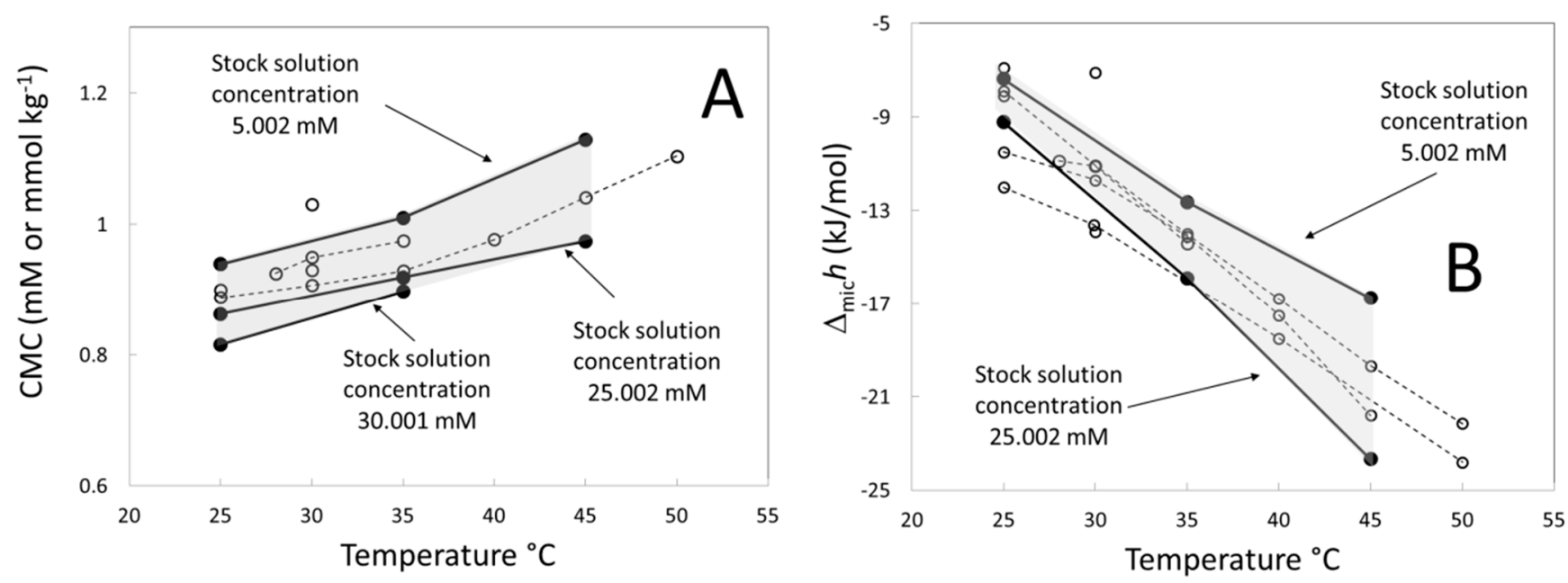

Figure 8. Comparison of literature data and data obtained in this work for C16-TAB. (A) Inflexion-points (full circles) and CMC values from the literature (open circles). (B) Step height measured the inflexion point (full circles) and enthalpies of micellization obtained from the literature (open circles).

Figure 9 shows the step height of the titration curves calculated by the two both methods exposed in the Material and Methods Section. No appreciable differences between methods were found. Figure 9A shows the step height as a function of the temperature for two stock solution concentrations. In both cases, the step height depends linearly on the temperature as in the case of the extrapolated value (Figure 6). Similar results, where the enthalpy of micelle formation is linear, or close to a linear behavior, was found by other authors [24,25]. From Figure 9A, the slope of the fit depends on the stock solution concentration indicating that the heat capacity calculated from this method will depend on the stock solution concentration. In addition to this, the arbitrariness of the micellization enthalpy calculated from the step height is evident because the value at $35^{\circ} \mathrm{C}$ for a stock solution concentration of $25.0 \mathrm{mM}$ is similar to that of $45^{\circ} \mathrm{C}$ for $5.0 \mathrm{mM}$. Figure $9 \mathrm{~B}$ shows the step height as a function of the stock solution concentration at several temperatures. In all cases, the step height decreases until a limiting value.
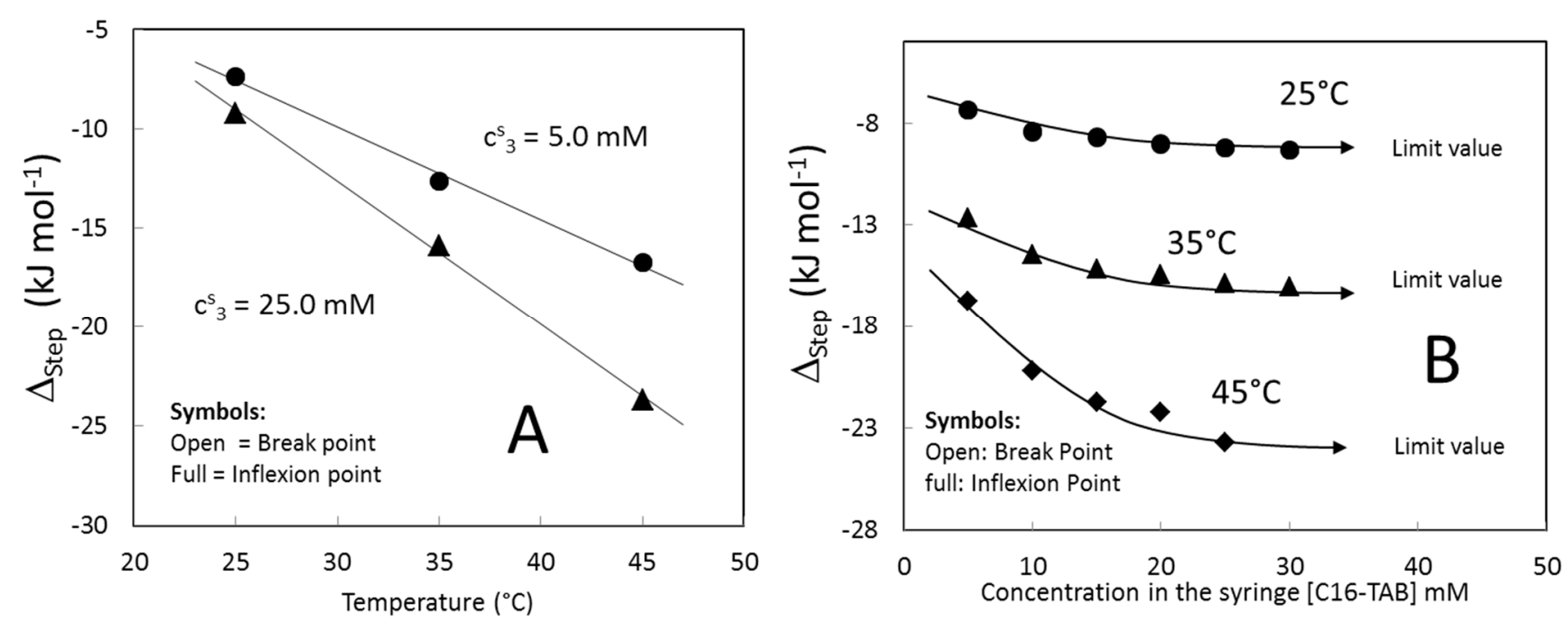

Figure 9. (A) Step height of C16-TAB measured at the inflexion point (full symbols) and measured at the break-point (open symbols) as function of the temperature at two stock solution concentrations. (B) Step height of C16-TAB measured at the inflexion point (full symbols) and measured at the break-point (open symbols) as function of the stock solution concentration for several stock solution concentrations. 
Figure 8B compares the step height values obtained in this work and literature values calculated by isothermal titration calorimetry using similar methods $[8,23,28,33-37]$ (Table S2 in Supplementary Material). Except for a few points between 25 and $30^{\circ} \mathrm{C}$, all data are between the values measured with the stock solution concentrations 5.0 and $25.0 \mathrm{mM}$ indicating that the dependency of the step height with the stock solution concentration can explain the scattering of the $\Delta_{\text {mic }} h$ literature data for the C16-TAB.

Usually, the micellization heat capacity $[24,25]$ is calculated by the slope in plots of the step height of titration curves as a function of the temperature. Figure 10 shows this amount $\mathrm{d} \Delta_{\text {Step }} / \mathrm{dT}$ (obtained by the two methods discussed in the Material and Method Section) as function of the stock solution concentration. Figure 10 shows that this amount decreases until a limit value when the stock solution concentration in the syringe increases.

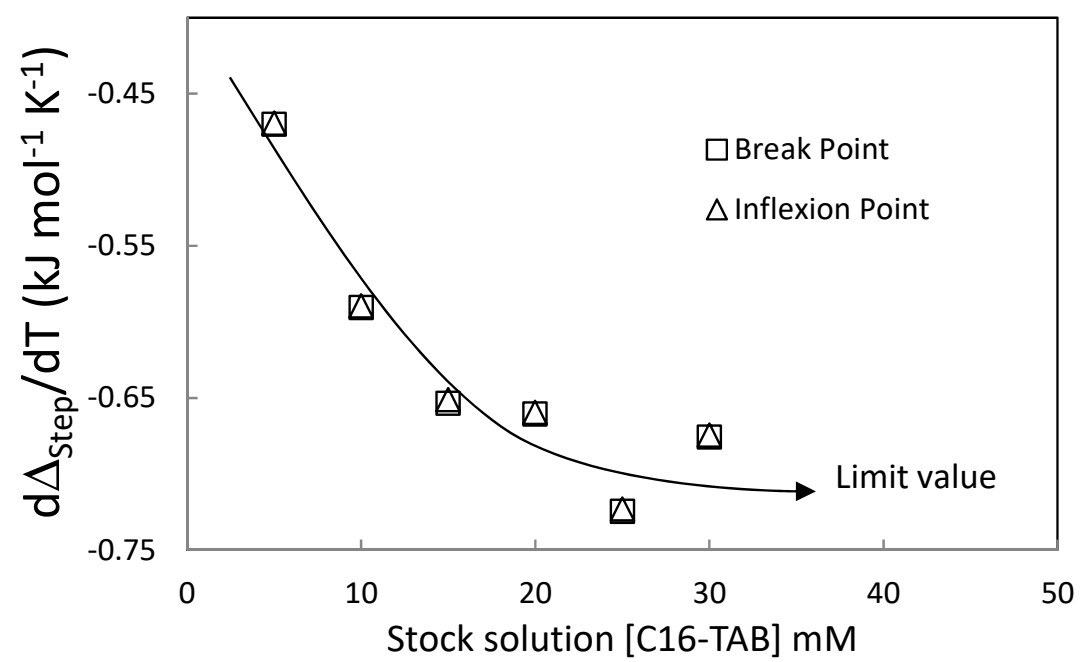

Figure 10. Slope of the step height with respect to the temperature $(\mathrm{d} \Delta \mathrm{step} / \mathrm{dT})$ as function of the stock solution concentration of C16-TAB.

Until now, we have seen that the stock solution concentration affects the magnitude and geometrical characteristics (break-point, inflexion-point, and step height) of the heat titration curve, but we have not studied the thermodynamic cause of this effect. It is possible to study qualitatively this behavior using the relative titration heat and considering the micellar system as a 2-component system in the monomer region and in the micellar region (without considering the details of the micelle formation).

Figure 11 shows the relative heat titration curve at several stock solution concentrations calculated using Equation (6) and values of the extrapolated value shown in Figure 6. In the monomer region, before the $C M C$, the system can be considered as composed of the solvent (component 1 ) and surfactant monomer in solution (component 2). Because in this region the relative heat capacity is zero independently of the stock solution concentration, by Equation (6) this region can be described by the following Equation:

$$
0=\frac{\rho^{s}-c_{2}^{s}}{c_{2}^{s}} l_{1 ; 2}\left(c_{2}\right)+l_{2 ; 1}\left(c_{2}\right)
$$

Differentiating with respect to $c_{2}$ in (12), considering the Gibbs-Duhem Equation for the relative enthalpy in a binary system:

$$
\left(\rho_{2}-c_{2}\right) \frac{d l_{1 ; 2}}{d c_{2}}+c_{2} \frac{d l_{2 ; 1}}{d c_{2}}=0
$$

where $\rho_{2}$ is the molar density of the system at the concentration $c_{2}$ and bearing in mind that $l_{1 ; 2}(0)=l_{2 ; 1}(0)=0$, it is obtained that both relative partial molar enthalpies of solvent and solute must be identically zero below CMC. This means that the system of C16-TAB 
in water behaves as an ideal solution in the monomer region independently of the stock solution concentration.

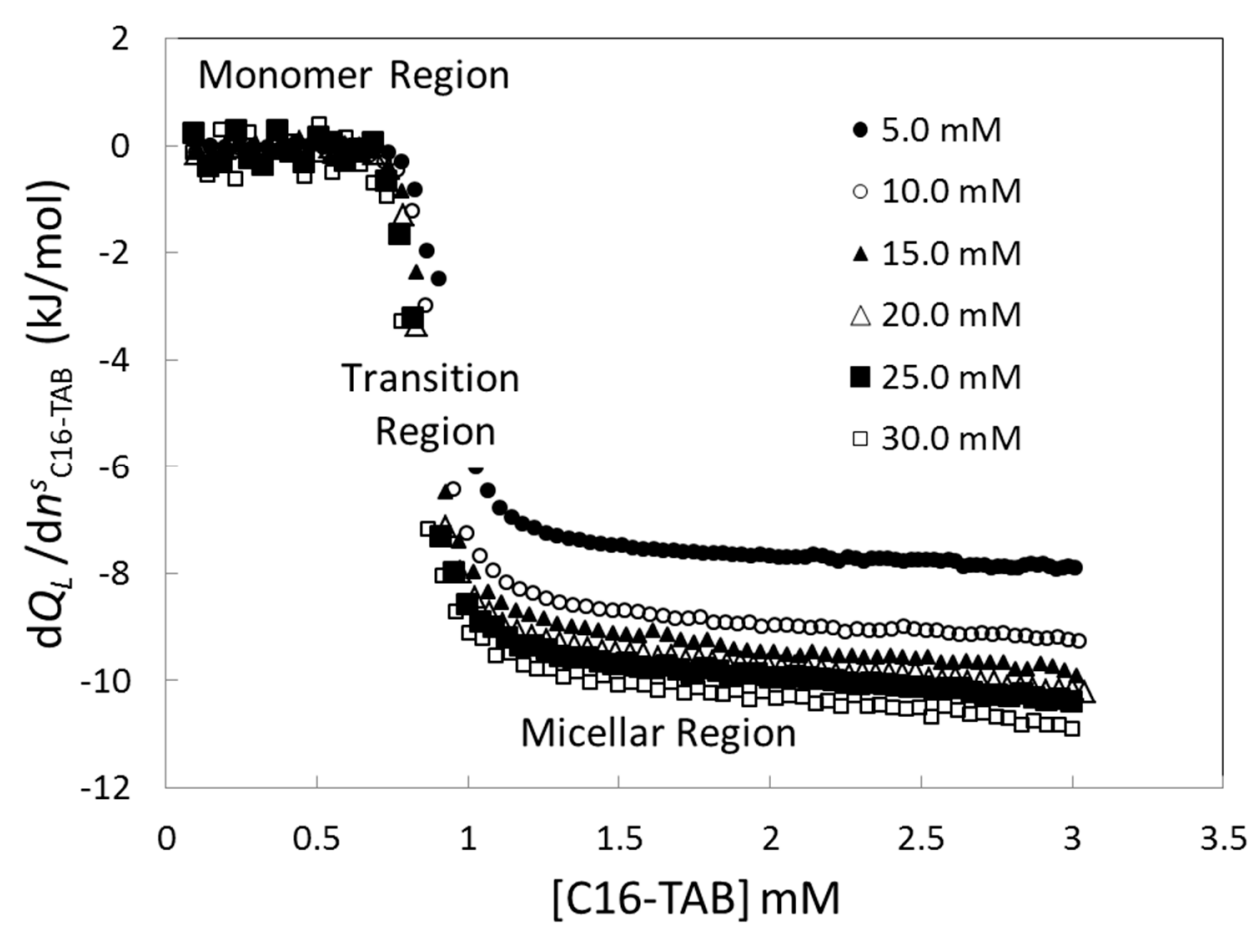

Figure 11. Relative titration heat of $\mathrm{C} 16-\mathrm{TAB}$ at $25^{\circ} \mathrm{C}$ at several stock solution concentrations.

After $C M C$ micelle formation is a consequence of solute-solute interaction. Appendix B shows that for a diluted solution with solute-solute interactions, the partial relative enthalpy of solute and solvent are not null and that the contribution of the relative partial enthalpy of solute is bigger than that of the relative partial enthalpy of solvent. For this reason, both non-zero contributions must be considered in Equation (6). In addition, considering that:

$$
\frac{\rho_{2}^{s}-c_{2}^{s}}{c_{2}^{s}}=\frac{1}{x_{2}^{s}}-1
$$

and substituting (14) in Equation (6) and taking the limit of $x^{s}{ }_{2}$ approaching to 1:

$$
\lim _{x_{2}^{s} \rightarrow 1} \frac{d Q_{L}}{d n_{2}^{s}}=l_{2 ; 1}
$$

Figure 11 shows that $d Q_{L} / d n_{s}$ decreases with the stock solution concentration until limiting curve. This behavior can be explained by means of Equation (15) because when the stock solution concentration increases enough, the relative heat of titration approaches to the relative partial enthalpy of solute. This result can explain the limiting values obtained for the inflexion point, break-point, and step height. For low stock solution concentrations, the contribution of the term $\left(\rho^{s}{ }_{2}-c^{s}{ }_{2}\right) / c^{s}{ }_{2}$ goes from 1850 (for $30.0 \mathrm{mM}$ ) to 11,000 (for $5.0 \mathrm{mM})$ and because the relative partial enthalpy is non-zero, the term $\left(\rho^{s}{ }_{2}-{c^{s}}_{2}\right) / c^{s}{ }_{2} \times l_{1 ; 2}$ can affect the value of relative heat of titration in Equation (6) explaining the general dependence of the inflexion point, break-point, and step height with the stock solution concentration. It is possible to understand this behavior evaluating all contributions with the following numerical example. Figure 12 shows the behavior of the relative titration heat at $25^{\circ} \mathrm{C}$ evaluated at one arbitrary concentration in the cell (for example $2 \mathrm{mM}$ ), as a function of the stock solution concentration in the syringe. The curve was calculated 
from the fit of the relative titration heat against the molar fraction of the stock solution concentration using the fit function:

$$
f(x)=\left(\frac{1}{x}-1\right) A+B
$$

where $A$ and $B$ are constant. The obtained values of the constants are $A=2.6 \times 10^{-4} \pm 0.1$ $\times 10^{-4} \mathrm{~kJ} / \mathrm{mol}$ and $B=-10.52 \pm 0.08 \mathrm{~kJ} / \mathrm{mol}$ and they can be interpreted, respectively, as the relative molar enthalpies of the solvent and the solute evaluated at the concentration of $2 \mathrm{mM}$. As it was stated by the theorem of Appendix B, the absolute value of the relative partial molar enthalpy of solute is five orders of magnitude bigger than the relative partial enthalpy of solvent. The solvent contribution to the relative titration heat is the term $\left(1 / x_{2}^{s}-1\right) \times l_{1 ; 2}$ and at the stock solution concentration of $5 \mathrm{mM}$ this term takes the value $2.88 \mathrm{~kJ} / \mathrm{mol}$ while at $30 \mathrm{mM}$ it decreases until $0.48 \mathrm{~kJ} / \mathrm{mol}$. Figure 12 shows clearly that the relative titration heat is the balance between the solvent contribution which decreases with the stock solution concentration and the solute contribution which is independent of the stock solution concentration. A possible explanation of the dependence of the titration heat with the stock solution concentration could be in terms of a possible change in the morphology of the aggregates in the stock solution. In this work, it was shown that the behavior exposed in Figure 12 can be explained by means of non-ideal solvent effects because the term $\left(1 / x^{s}{ }_{2}-1\right) \times l_{1 ; 2}$ increases very fast when the stock solution concentration decreases. In addition to this, the asymptotic behavior can be easily understood in the following and intuitive terms. As it was said the titration heat is exactly the relative molar enthalpy when the titrant is a pure compound. When the stock solution concentration increases, the titrant approaches the pure compound of solute. For this reason, the titrant heat approaches the relative enthalpy of solute.

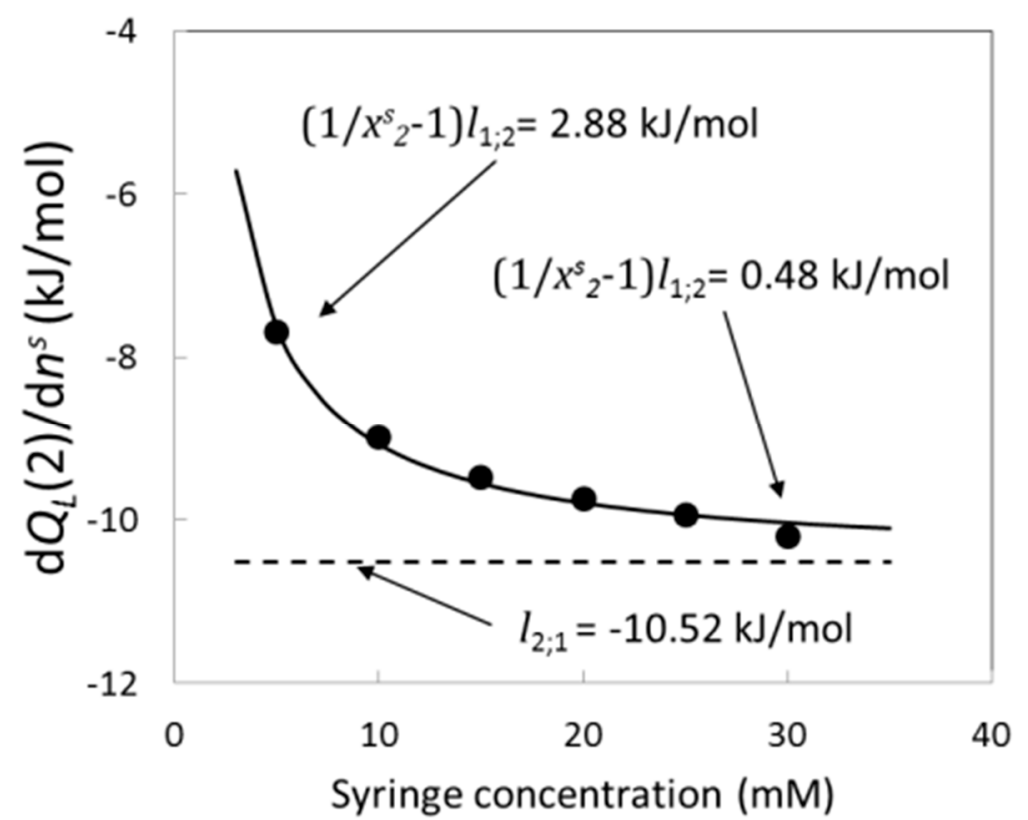

Figure 12. Relative titration heat of $\mathrm{C} 16-\mathrm{TAB}$ at $25{ }^{\circ} \mathrm{C}$ evaluated at the concentration of $2 \mathrm{mM}$ as function of the stock solution concentration in the syringe. The value $\left(1 / x_{2}{ }_{2}-1\right) l_{1 ; 2}$ is the solvent contribution to the relative titration heat. Full circles represent the relative titration heats and the curve is the fit calculated by Equation (16).

About the concept of $C M C$, Charles Tanford [39] wrote around fifty years ago: “The concept of a "critical micelle concentration" for the formation of micelles from free amphiphile is inexact but convenient. The use of this concept is probably a major cause of confusion in the thermodynamic analysis of micelle-forming system ... It is customary to 
define a single concentration within this transition zone as a critical micelle concentration, generally abbreviated as "CMC." This is usually done by empirical graphical procedures. These graphical methods were basically proposed by Williams [40] and by Phillips [41] around seventy years ago. In Williams's approach $[40,42]$ the critical micelle concentration is obtained by the intercept of the extrapolations from both monomer region and micellar region using data from an experimental technique as a function of the surfactant concentration. In this work, we have used this approach implemented in the method of break-point. In the Phillips approach, the $C M C$ is defined as the concentration of surfactant in the inflexion point of a particular property measured experimentally:

$$
\left(\frac{d^{3} \phi}{d c_{T^{3}}}\right)_{c=C M C}=0
$$

where $\phi$ is a property measured experimentally and $c_{T}$ is the total concentration of surfactant. In this work, we have used this approach implemented in the method of "inflexionpoint". The CMC, such as was defined by Williams and Phillips (and discussed by Tanford), is intimately linked to a particular experimental technique. In this work, we have shown experimental evidence about the dependence of the titration curve with the stock solution concentration. If the $C M C$ is defined as a geometrical characteristic of the titration curve obtained from a graphical method (break-point or inflexion-point), a concept of CMC which depends on the stock solution concentration is obtained. The concept of micellization enthalpy is different because it is defined as:

$$
\Delta_{\text {mic }} h=h_{\text {mic }}^{o}-h_{\text {mon }}^{o}
$$

where $h^{o}{ }_{\text {mic }}$ and $h^{o}$ mon are, respectively, the standard enthalpies of the surfactant in micellar state and in monomeric state. By Equation (18) the micellization enthalpy only depends on substance, indicating that any systematic error is associated with the graphical method used. A way to avoid the dependence of $C M C$ and $\Delta_{\text {mic }} h$ with the stock solution concentration is by the employment of theoretical models. This discussion resembles, somehow, the way used in ligand binding studies where the binding equilibrium constant and the binding enthalpy are calculated by different theoretical models. In the simplest case of the interaction of ligand and a macromolecule with a stoichiometry $1: 1$, studied by means of the Wiseman Isotherm [43], the characteristics of the titration curve depend dramatically on Brandt's parameter [44,45] defined as:

$$
c=c_{M} K_{\text {Bind }}
$$

where $c_{M}$ is the concentration of macromolecule and $K_{B i n d}$ is the binding equilibrium constant. Graphical methods are not used in this case because the shape and magnitude of the titration curve depends on the experimental design expressed in terms of Brandt's parameter. In addition to this, the value of this parameter affects the precision and reliability of the values of binding enthalpy and binding equilibrium constant obtained by fit of theoretical models and some authors have proposed different ranges of $\mathrm{c}$ in order to get the optimum value of this experimental parameter [45-47].

As it was said, the titration curve approaches the relative partial molar enthalpy of solute when the stock solution concentration increases. To use high stock solution concentrations could be a way to avoid systematic errors in the determinations of $C M C$ and $\Delta_{\text {mic }} h$. The problem of this way is that titration volumes would be very small and other systematic errors will appear due to the lack of control in the automatic titration system to give an exact volume. From an operational point of view many times it is not possible to carry out a study similar to that of this work in order to determine the better value of the stock solution concentration. Based upon the fact that in general the shape and magnitude of the titration curve depend on the experimental design, the solution of this problem is to use the theoretical model (as in the case of ligand binding). This is 
the most recommended procedure to determine the critical micelle concentration and the micellization enthalpy by isothermal titration calorimetry, in special for shorter alkyl chains for which the micellization transition is not so steep (cooperative). For this reason, theoretical models including the stock solution concentration effect [32] should be used to obtain the CMC and $\Delta_{\text {mic }} h$ because if this effect is not considered [48], systematic errors could be present in the results.

\section{Conclusions}

In this work, we have studied the influence of the titration process on the determination of the micellar properties using a robotic calorimeter.

It was found that the magnitude and shape of the heat titration curve depend on the stock solution concentration. As consequence geometric characteristics as inflexion point, break-point, and step height depend on the stock solution concentration. For high stock solution concentrations in 2-component systems, the relative heat titration curve approaches to the relative partial enthalpy of solute. This fact can explain the fact that inflexion point, break-point, and step height approach limiting values when the stock solution concentration increases.

As a practical rule, it was proposed that there is a balance between the stock solution concentration and the injection volume. The stock solution concentration should be as big as possible to decrease the effect of non-ideality of the solvent while the injection volume should be as big as possible to improve the control in the injection volume.

In this work, it was found that the calculation of $C M C$ and $\Delta_{m i c} h$ by graphical methods can include systematic errors because the dependence of the titration heat on the stock solution concentration in the syringe. This effect is produced by the non-ideal behavior of the solvent after the CMC.

Theoretical models on micelle formation should describe the exposed phenomenology. In this way, they could be used in the future to obtain the critical micelle concentration and the micellization enthalpy from experimental titration curves without systematic errors.

Supplementary Materials: The following are available online at https: / /www.mdpi.com/1099-4 300/23/2/236/s1, Table S1: Critical micelle concentration of C16-TAB taken from the bibliography using isothermal titration calorimetry with the same experimental design., Table S2: Micellization enthalpy of C16-TAB taken from the bibliography using isothermal titration calorimetry with the same experimental design.

Author Contributions: M.C. collected and interpreted data, prepared samples for experiments, made experiments and was responsible for maintenance of ITC experiment. R.J.-J. collected and interpreted data, synthesized surfactants, prepared samples for experiments and made experiments. G.M.-M. collected and interpreted data, synthesized surfactants, prepared samples for experiments and made experiments. M.d.J.M.-O. collected and interpreted data, prepared samples for experiments and made experiments. J.M.d.R. is the author of the conception and design of the study. J.M.d.R. coordinated the study, collected and interpreted data, design the methodology, prepared samples for experiments and made experiments. The manuscript was written by J.M.d.R. and M.C. and revised by R.J.-J., G.M.-M. and M.d.J.M.-O. All authors read and approved the final version of the manuscript.

Funding: This research was funded by the Instituto Politécnico Nacional (SIP Project 20201730) and by COFAA-IPN.

Institutional Review Board Statement: Not applicable.

Informed Consent Statement: Not applicable.

Acknowledgments: To Glenn Hefter for his deep revision of the manuscript and his interesting comments and suggestions to improve it. To Pedro Daniel Carteño Ventura for the the carefully preparation of the stock solutions of Table 1.

Conflicts of Interest: The authors declare no conflict of interest. 


\section{Appendix A.}

As it was said in the main body of this work, the standard method to calculate the enthalpy of micelle formation by isothermal titration calorimetry was proposed by van Os et at [13]. This method was taken from previous works of the Desnoyer's group [14,15] who developed it to be applied using Picker calorimeters $[16,17]$. This supporting information deals with the study in detail of thermodynamic fundaments of this graphical method.

Appendix A.1. Demonstration as Given in the Paper Can. J. Chem. 1980, 58, 959-969

This section shows the original demonstration as it was given in the reference [15]. The total relative enthalpy of the solution above the $C M C$ is given by:

$$
L=\sum_{i} n_{i} L_{i}=n_{w} L_{w}+n_{s} L_{s}+n_{m} L_{m}=55.51 L_{w}+C M C L_{s}+(m-C M C) L_{m}
$$

where the subscript $w$ refers to water. Equation (A1) implies that the concentration of monomers remains constant beyond the $C M C$. The value of $L^{a}{ }_{2}$ above the $C M C$ is then by

$$
L_{2}^{a}=\left(\frac{\partial L}{\partial m}\right)_{T, P}=L_{m}+55.51\left(\frac{\partial L_{w}}{\partial m}\right)+C M C\left(\frac{\partial L_{s}}{\partial m}\right)+(m-C M C)\left(\frac{\partial L_{m}}{\partial m}\right)
$$

In the pre-micellar region the relative molar enthalpies of the solution are given by

$$
L=55.51 L_{w}+m L_{s}
$$

And the value $L^{a}{ }_{2}$ below the $C M C$ is given by:

$$
L_{2}^{b}=L_{s}+55.51\left(\frac{\partial L_{W}}{\partial m}\right)+m\left(\frac{\partial L_{s}}{\partial m}\right)
$$

Combining Equation (A2) and (A4)

$$
L_{2}^{a}-L_{2}^{b}=L_{m}-L_{s}+(m-C M C)\left(\frac{\partial\left(L_{m}-L_{s}\right)}{\partial m}\right)=\Delta H_{m}+(m-C M C)\left(\frac{\partial \Delta H_{m}}{\partial m}\right)
$$

At the $C M C$ it is therefore correct to identify $L^{a}{ }_{2}-L^{b}{ }_{2}$ with $\Delta H_{m}$.

\section{Appendix A.2. Method Based upon the Gibbs Equation}

In the demonstration of Equation (A5) it is assumed implicitly that micellar system can be described in two ways and that two both descriptions are equivalents.

First description considers the system as composed of the solvent (component 1 ) and the surfactant as solute (component 2). In this description the system is considered as a 2-component system where the relative enthalpy $L$ is written as:

$$
L=L\left(n_{1}, n_{2}\right)
$$

being $n_{1}$ and $n_{2}$ the number of moles of component 1 and 2, respectively. The Gibbs Equation for the relative enthalpy is:

$$
d L=\left(\frac{\partial L}{\partial n_{1}}\right)_{n_{2}} d n_{1}+\left(\frac{\partial L}{\partial n_{2}}\right)_{n_{1}} d n_{2}
$$

From Equation (A7) the relative molar partial enthalpies of solvent and solute are defined as:

$$
\begin{aligned}
& L_{1}=\left(\frac{\partial L}{\partial n_{1}}\right)_{n_{2}} \\
& L_{2}=\left(\frac{\partial L}{\partial n_{2}}\right)_{n_{1}}
\end{aligned}
$$


and then Equation (A7) takes the form:

$$
d L=L_{1} d n_{1}+L_{2} d n_{2}
$$

By convenience we will consider that system is composed by a constant amount of water (equal to the number of moles of $1 \mathrm{~kg}$ of water, $n^{0}{ }_{1}$ ) and a variable amount of solute, so $n_{2}$ will be equal to the molality of the solute $(\mathrm{m})$ and then:

$$
d L=L_{2} d m
$$

because $d n_{1}=0$. Equation (A10) also can be written as:

$$
\left.\frac{d L}{d m}\right|_{n_{1}=n_{1}^{0}}=L_{2}
$$

where we are indicating that the total differential is evaluated at constant number of solvent moles equal to $n^{0}{ }_{1}$. In this study, before the $C M C$ Equation (A11) will take the form:

$$
\left.\frac{d L^{b}}{d m}\right|_{n_{1}=n_{1}^{0}}=L_{2}^{b}
$$

and after the $C M C$ it will take the form:

$$
\left.\frac{d L^{a}}{d m}\right|_{n_{1}=n_{1}^{0}}=L_{2}^{a}
$$

Subtracting (A12) from (A13) gives:

$$
\left.\frac{d L^{a}}{d m}\right|_{n_{1}=n_{1}^{0}}-\left.\frac{d L^{b}}{d m}\right|_{n_{1}=n_{1}^{0}}=L_{2}^{a}-L_{2}^{b}
$$

In the second description, the system is considered as composed of the solvent (component $\mathrm{w}$ ), the surfactant in monomer or single state (component s) and surfactant in micellar state (component $\mathrm{m}$ ). In this way the relative enthalpy is written as:

$$
L=L\left(n_{1}, n_{s}, n_{m}\right)
$$

being $n_{s}$ and $n_{m}$ the number of moles of the surfactant in monomer state and in micellar state respectively where

$$
n=n_{s}+n_{m}
$$

is total number of moles of surfactant in the system. In this description the Gibbs Equation for $L$ is:

$$
d L=\left(\frac{\partial L}{\partial n_{w}}\right)_{n_{s}, n_{m}} d n_{w}+\left(\frac{\partial L}{\partial n_{s}}\right)_{n_{w}, n_{m}} d n_{s}+\left(\frac{\partial L}{\partial n_{m}}\right)_{n_{w}, n_{s}} d n_{m}
$$

From Equation (A17) the partial properties of components of the system (which are intensive properties depending only on the composition system) are defined as:

$$
\begin{aligned}
L_{w} & =\left(\frac{\partial L}{\partial n_{w}}\right)_{n_{s}, n_{m}} \\
L_{s} & =\left(\frac{\partial L}{\partial n_{s}}\right)_{n_{w}, n_{m}} \\
L_{m} & =\left(\frac{\partial L}{\partial n_{m}}\right)_{n_{w}, n_{s}}
\end{aligned}
$$

and then the total differential of the relative enthalpy can be written as:

$$
d L=L_{w} d n_{w}+L_{s} d n_{s}+L_{m} d n_{m}
$$


In the model proposed by the Desnoyer's group, before the CMC all surfactant is free in solution without form micelles and then:

$$
\text { before } C M C \Rightarrow\left\{\begin{array}{l}
n_{s}=n \Rightarrow d n_{s}=d n \\
n_{m}=0 \Rightarrow d n_{m}=0
\end{array}\right.
$$

Substituting (A20) in (A19):

$$
d L^{b}=L_{w} d n_{w}+L_{s} d n
$$

By convenience we will consider that the amount of water is the number of moles of $1 \mathrm{~kg}$ of water and the number of moles of surfactant is the molality and then:

$$
\begin{gathered}
n_{w}=n_{w}^{0} \Rightarrow d n_{w}=0 \\
n=m \Rightarrow d n=d m
\end{gathered}
$$

By substitution of (A22) in (A21) one gets:

$$
d L^{b}=L_{s} d m
$$

or:

$$
\left.\frac{d L^{b}}{d m}\right|_{n_{1}=n_{1}^{0}}=L_{s}
$$

After the $C M C$, the amounts of surfactant in the monomer state and in micellar state are:

$$
\text { after } C M C \Rightarrow\left\{\begin{array}{c}
n_{s}=n_{C M C} \\
n_{m}=n-n_{C M C}
\end{array}\right.
$$

where $n_{C M C}$ is the number of moles at the $C M C$ (monomer state). The application of this model to Equation (19) gives:

$$
d L^{a}=L_{w} d n_{w}+L_{m} d n_{m}
$$

Now we will consider for convenience that the amount of water is the number of moles of $1 \mathrm{~kg}$ of water. In this way, the total amount of solute is the molality of the surfactant and then:

$$
\begin{gathered}
n_{w}=n_{w}^{0} \Rightarrow d n_{w}=0 \\
n_{m}=n-n_{C M C}=m-m_{C M C} \Rightarrow d n_{m}=d m
\end{gathered}
$$

Substituting (A27) in Equation (A26):

$$
d L^{a}=L_{m} d m
$$

or:

$$
\left.\frac{d L^{a}}{d m}\right|_{n_{1}=n_{1}^{0}}=L_{m}
$$

By subtraction of Equation (A24) from Equation (A29) one gets:

$$
\begin{aligned}
& L_{2}^{a}-L_{2}^{b}=L_{m}-L_{s} \\
& =\Delta H_{\mathrm{m}}
\end{aligned}
$$

It is interesting to observe that after the application of the model of the Dersnoyer's group the general Equation (A6) and (A15) the term $\left(m-m_{C M C}\right)\left(\partial \Delta H_{\mathrm{m}} / \partial \mathrm{m}\right)$ does not appear in the final Equation (A30). 
Appendix A.3. Method Based upon the Gibbs-Duhem Equation

From Equation (A15) and considering that $L$ is an homogeneous function of one degree of the variables $n_{w}, n_{s}$ and $n_{m}$, the Euler Equation of $L$ is:

$$
L=n_{w}\left(\frac{\partial L}{\partial n_{w}}\right)_{n_{s}, n_{m}}+n_{s}\left(\frac{\partial L}{\partial n_{s}}\right)_{n_{w}, n_{m}}+n_{m}\left(\frac{\partial L}{\partial n_{m}}\right)_{n_{w}, n_{s}}=n_{w} L_{w}+n_{s} L_{s}+n_{m} L_{m}
$$

The Gibbs-Duhem Equation is obtained calculating in (A31) the total differential of $L$, equaling to (A19) and reorganizing:

$$
n_{w} d L_{w}+n_{s} d L_{s}+n_{m} d L_{m}=0
$$

Now we will apply the model proposed by the Dersnoyer's group to the Equation (A32). Before the CMC all surfactant is in single state and the amount of micelles is zero:

$$
\text { before } C M C \Rightarrow\left\{\begin{array}{c}
n_{s}=n \\
n_{m}=0
\end{array}\right.
$$

and then Equation (A32) takes the form:

$$
n_{w} d L_{w}+n d L_{s}=0
$$

Considering that $L_{w}$ and $L_{s}$ are intensive properties which only depend on the composition of the system:

$$
\begin{gathered}
L_{w}=L_{w}(m) \Rightarrow d L_{w}=\left(\frac{d L_{w}}{d m}\right) d m \\
L_{s}=L_{s}(m) \Rightarrow d L_{s}=\left(\frac{d L_{s}}{d m}\right) d m
\end{gathered}
$$

By substitution of (A35) in (A34) we have that:

$$
\left[n_{w} \frac{d L_{w}}{d m}+n \frac{d L_{s}}{d m}\right] d m=0 \Rightarrow n_{w} \frac{d L_{w}}{d m}+n \frac{d L_{s}}{d m}=0
$$

By convenience we will consider in (A36) that the amount of water is $n_{w}^{0}=55.51$ moles, so the amount number of moles of surfactant is equal to its molality and then:

$$
n_{w}^{0} \frac{d L_{w}}{d m}+m \frac{d L_{s}}{d m}=0
$$

Substituting the result obtained in (A37) in the original Equation obtained by the Desnoyer's group before the CMC (A4) we obtain the correct form of the Equation (A4):

$$
L_{2}^{b}=L_{s}
$$

After the $C M C$ :

$$
\text { after } C M C \Rightarrow\left\{\begin{array}{c}
n_{s}=n_{C M C} \\
n_{m}=n-n_{C M C}
\end{array}\right.
$$

and applying (A39) to the Gibss-Duhem Equation (A32) one gets:

$$
n_{w} d L_{w}+n_{C M C} d L_{s}+\left(n-n_{C M C}\right) d L_{m}=0
$$


In the model proposed by the Desnoyer's group, the composition of the system above the $C M C$ is completely determined by the total molality $\mathrm{m}$ of the surfactant and because the partial properties only depend on the composition:

$$
\begin{gathered}
L_{w}=L_{w}(m) \Rightarrow d L_{w}=\left(\frac{d L_{w}}{d m}\right) d m \\
L_{s}=L_{s}(m) \Rightarrow d L_{s}=\left(\frac{d L_{s}}{d m}\right) d m \\
L_{m}=L_{m}(m) \Rightarrow d L_{m}=\left(\frac{d L_{s}}{d m}\right) d m
\end{gathered}
$$

Substituting (A41) in (A40) and reorganizing:

$$
\left[n_{w} \frac{d L_{w}}{d m}+n_{C M C} \frac{d L_{s}}{d m}+\left(n-n_{C M C}\right) \frac{d L_{m}}{d m}\right] d m=0
$$

and then:

$$
n_{w} \frac{d L_{w}}{d m}+n_{C M C} \frac{d L_{s}}{d m}+\left(n-n_{C M C}\right) \frac{d L_{m}}{d m}=0
$$

If by convenience we consider that the amount of moles water is $n^{0}{ }_{w}=55.51$ moles then:

$$
n_{w}^{0} \frac{d L_{w}}{d m}+m_{C M C} \frac{d L_{s}}{d m}+\left(m-m_{C M C}\right) \frac{d L_{m}}{d m}=0
$$

Substituting now the result of the Equation (A44) in the original Equation obtained by the Dersnoyer's group Equation (A2) we have that:

$$
L_{2}^{a}=L_{m}
$$

With this, the correct form of the Equation (A5) is:

$$
L_{2}^{a}-L_{2}^{b}=L_{m}-L_{s}=\Delta H_{m}
$$

As we have seen the Equation:

$$
L_{2}^{a}-L_{2}^{b}=\Delta H_{m}+(m-C M C)\left(\frac{\partial \Delta H_{m}}{\partial m}\right)
$$

is an artifact which correct form is:

$$
L_{2}^{a}-L_{2}^{b}=\Delta H_{m}
$$

Equation (A48) is not useful as a graphical method because if $L^{a}{ }_{2}$ and $L^{b}{ }_{2}$ are not parallel, the difference $L^{a}{ }_{2}-L^{b}{ }_{2}$ will depend on concentration given a value of $\Delta H_{m}$ completely indeterminate. The calculation error in the original demonstration $[14,15]$ was caused because $L^{a}{ }_{2}$ and $L_{2}^{b}$ are calculated using the Euler Equation of $L$, without to apply the corresponding Gibbs-Duhem Equation, to remove terms which are null. This error is produced by the use of an oversimplified notation. Due to the lack of a true thermodynamic foundation the graphical method discussed must be considered as an empirical rule.

\section{Appendix B.}

Thermodynamic Theorem A1. Let there be a diluted solution of component 2 (solute) in 1 (solvent) with solute-solute interactions, then the contribution of the relative partial molar enthalpy of the solvent is not null and much smaller than that of the solute. 
Proof of Thermodynamic Theorem A1. The Gibbs-Duhem Equation for the enthalpy in a 2-component system can be written on the mole fraction scale as:

$$
x_{1} \frac{d l_{1 ; 2}}{d x_{2}}+x_{2} \frac{d l_{2 ; 1}}{d x_{2}}=0
$$

If solute-solute interactions are considered then $d l_{2 ; 1} / d x_{2}$ is not null and then $d l_{1 ; 2} / d x_{2}$ is also not null. Considering a diluted solution where $x_{1}<<x_{2}$ and supposing that $d l_{2 ; 1} / d x_{2}$ is positive, we have that:

$$
0<-\frac{d l_{1 ; 2}}{d x_{2}}<<\frac{d l_{2 ; 1}}{d x_{2}}
$$

By integrating Equation (A50) in the interval $\left[0, x_{2}\right]$ it is obtained that:

$$
0<-\int_{0}^{x_{2}}\left(\frac{d l_{1 ; 2}}{d x_{2}^{\prime}}\right) d x_{2}^{\prime}{ }_{2}<<\int_{0}^{x_{2}}\left(\frac{d l_{2 ; 1}}{d x_{2}^{\prime}}\right) d x_{2}^{\prime}
$$

and then:

$$
0<-l_{1 ; 2}<<l_{2 ; 1}
$$

With similar arguments for a negative $d l_{2 ; 1} / d x_{2}$, it is arrived at the general result:

$$
0<\left|l_{1 ; 2}\right|<<\left|l_{2 ; 1}\right|
$$

\section{References}

1. del Rio, J.M.; Grolier, J.-P.E. Chapter 4: Isothermal Titration Calorimetry. In Enthalpy and Internal Energy, Liquid, Solutions, and Vapours; Wilhelm, E., Letcher, T.M., Eds.; Royal Society of Chemistry: London, UK, 2018.

2. Grolier, J.-P.E.; del Río, J.M. Isothermal titration calorimetry: A thermodynamic interpretation of measurements. J. Chem. Thermodyn. 2012, 55, 193-202. [CrossRef]

3. Sarge, S.M.; Höhne, G.W.H.; Hemminger, W. Calorimetry: Fundamentals, Instrumentation and Applications; Wiley-VCH Verlag GmbH \& Co. KgaA: Weinheim, Germany, 2014; Chapter 5; p. 73.

4. Koga, Y. Excess partial molar enthalpies of tert-butanol in water in water-tert-butanol mixtures. J. Can. Chem. 1988, 66, 1187-1193. [CrossRef]

5. Matteoli, E.; Lepori, L. Determination of the excess enthalpy of binary mixtures from the measurements of the heat of solution of the components: Application to the perfluorohexane + hexane mixture. Fluid Phase Equilb. 2000, 174, 115-131. [CrossRef]

6. Olofsson, G. Microtitration calorimetric study of the micellization of three poly (oxyethylene) glycol dodecyl ethers. J. Phys. Chem. 1985, 89, 1473-1477. [CrossRef]

7. Johnson, I.; Olofsson, G. Thermodynamics of micelle formation of alkali-metal perfluorononanates in water. Comparison with hydrocarbon analogues. J. Chem. Soc. Faraday Trans. 1988, 84, 551-560. [CrossRef]

8. Bergström, S.; Olofsson, G. A calorimetric study of three long-chain ionic surfactants. Thermochim. Acta 1986, 109, $155-164$. [CrossRef]

9. Karumbamkandathil, A.; Ghosh, S.; Anand, U.; Saha, P.; Mukherjee, M.; Mukherjee, S. Micelles of benzethonium chloride undergoes spherical to cylindrical shape transformation: An intrinsic fluorescence and calorimetric approach. Chem. Phys. Lett. 2014, 593, 115-121. [CrossRef]

10. Łudzik, K.; Woloszczuk, S.; Zajac, W.; Jazdzewska, M.; Rogachev, A.; Kuklin, A.I.; Zawisza, A.; Jóźwiak, M. Can the Isothermal Calorimetric Curve Shapes Suggest the Structural Changes in Micellar Aggregates? Int. J. Mol. Sci. 2020, 21, 5828. [CrossRef]

11. Olofsson, G.; Loh, W. On the use of Titration Calorimetry to Study the Association of Surfactants in Aqueous Solutions. J. Braz. Chem. Soc. 2009, 20, 577-593. [CrossRef]

12. Loh, W.; Brinatti, C.; Tam, K.C. Use of isothermal titration calorimetry to study surfactant aggregation in colloidal systems. Biochim. Biophys. Acta 2016, 1860, 999-1016. [CrossRef]

13. van Os, N.M.; Daane, G.J.; Haandrikmann, G. The effect of chemical structure upon the thermodynamics of micellization of model alkylarenesulfonates: III. Determination of the critical micelle concentration and the enthalpy of demicellization by means of microcalorimetry and a comparison with the phase separation model. J. Colloid Interface Sci. 1991, 141, 199-217.

14. Desnoyers, J.E.; DeLisi, R.; Perron, G. Thermochemistry of aqueous micellar systems. Pure Appl. Chem. 1980, 52, $433-444$. [CrossRef] 
15. De Lisi, R.; Perron, G.; Desnoyers, J.E. Volumetric and thermochemical properties of ionic surfactants: Sodium decanoate and octylamine hydrobromide in water. Can. J. Chem. 1980, 58, 959-969. [CrossRef]

16. Picker, P.; Jolicoeur, C.; Desnoyers, J. Steady state and composition scanning differential flow microcalorimeters. J. Chem. Thermodyn. 1969, 1, 469-483. [CrossRef]

17. Fortier, J.-L.; Leduc, P.-A.; Picker, P.; Desnoyers, J.E. Enthalpies of dilution of electrolyte solutions by flow microcalorimetry. J. Solut. Chem. 1973, 2, 467-475. [CrossRef]

18. del Rio, J.M.; Pombo, C.; Prieto, G.; Sarmiento, F.; Mosquera, V. n-Alkyltrimethylammonium bromides in a buffered medium: A thermodynamic investigation. J. Chem. Thermodyn. 1994, 26, 879-887. [CrossRef]

19. Mosquera, V.; del Rio, J.M.; Attwood, D.; Garcia, M.; Jones, M.N.; Prieto, G.; Suarez, M.J.; Sarmiento, F. A study of the aggregation behavior of hexyltrimethylammonium bromide in aqueous solution. J. Colloid Interface Sci. 1998, 206, 66-76. [CrossRef]

20. D'Andrea, M.G.; Domingues, C.C.; Malheiros, S.V.P.; Neto, F.G.; Barbosa, L.R.S.; Itri, R.; Almeida, F.C.L.; De Paula, E.; Bianconi, M.L. Thermodynamic and structural characterization of zwitterionic micelles of the membrane protein solubilizing amidosulfobetaine surfactants ASB-14 and ASB-16. Langmuir 2011, 27, 8248-8256. [CrossRef]

21. Giacomelli, C.E.; Vermeer, A.W.P.; Norde, W. Micellization and adsorption characteristics of CHAPS. Langmuir 2000, 16, 4853-4858. [CrossRef]

22. Blandamer, M.J.; Briggs, B.; Cullis, P.M.; Engberts, J.B.F.N. Titration microcalorimetry of mixed alkyltrimethylammonium bromide surfactant aqueous solutions. Phys. Chem. Chem. Phys. 2000, 2, 5146-5153. [CrossRef]

23. Chaghi, R.; de Ménorval, L.C.; Charnay, C.; Derrien, G.; Zajac, J. Interactions of phenol with cationic micelles of hexadecyltrimethylammonium bromide studied by titration calorimetry, conductimetry, and ${ }^{1} \mathrm{H}$ NMR in the range of low additive and surfactant concentrations. J. Colloid Interface Sci. 2008, 326, 227-234. [CrossRef]

24. Paula, S.; Sues, W.; Tuchtenhagen, J.; Blume, A. Thermodynamics of Micelle Formation as a Function of Temperature: A High Sensitivity Titration Calorimetry Study. J. Phys. Chem. 1995, 99, 11742-11751. [CrossRef]

25. Kresheck, G.C. Comparison of the Calorimetric and van't Hoff Enthalpy of Micelle Formation for a Nonionic Surfactant in $\mathrm{H}_{2} \mathrm{O}$ and $\mathrm{D}_{2} \mathrm{O}$ Solutions from 15 to $40^{\circ} \mathrm{C}$. J. Phys. Chem. B 1998, 102, 6596-6600. [CrossRef]

26. Király, Z.; Dekány, I. A Termodynamic Titration Study on the Micelle Formation of Sodium Decyl Sulfate in Water. J. Colloid Interface Sci. 2001, 242, 214-219. [CrossRef]

27. Textor, M.; Keller, S. Automated analysis of calorimetric demicellization titrations. Anal. Biochem. 2015, 485, 119-121. [CrossRef] [PubMed]

28. Moulik, S.P.; Mitra, D. Amphiphile self-aggregation: An attempt to reconcile the agreement-disagreement between the enthalpies of micellization determined by the van't Hoff and Calorimetry methods. J. Colloid Interface Sci. 2009, 337, 569-578. [CrossRef] [PubMed]

29. Garidel, P.; Hildebrand, A.; Neubert, R.; Blume, A. Thermodynamic Characterization of Bile Salt Aggregation as a Function of Temperature and Ionic Strength Using Isothermal Titration Calorimetry. Langmuir 2000, 16, 5267-5275. [CrossRef]

30. Klotz, I.M.; Rosenberg, R.M. Chemical Thermodynamics: Basic Theory and Methods, 6th ed.; John Wiley \& Sons: New York, NY, USA, 2000; Chapter 18; p. 413.

31. Tellinghuisen, J. Calibration in isothermal titration calorimetry: Heat and cell volume from heat of dilution of $\mathrm{NaCl}(\mathrm{aq})$. Anal. Biochem. 2007, 360, 47-55. [CrossRef]

32. Heintz, A.; Lehmann, J.K.; Kozlova, S.A.; Balantseva, E.V.; Bazyleva, A.B.; Ondo, D. Micelle formation of alkylimidazolium ionic liquids in water and in ethylammonium nitrate ionic liquid: A calorimetric study. Fluid Phase Equilib. 2010, $294,187-196$. [CrossRef]

33. Lah, J.; Pohar, C.; Vesnaver, G. Calorimetric Study of the Micellization of Alkylpyridinium and Alkyltrimethylammonium Bromides in Water. J. Phys. Chem. B 2000, 104, 2522-2526. [CrossRef]

34. Jiang, N.; Li, P.; Wang, Y.; Wang, J.; Yan, H.; Thomas, R.K. Aggregation behavior of hexadecyltrimethylammonium surfactants with various counterions in aqueous solution. J. Colloid Interface Sci. 2005, 286, 755-760. [CrossRef] [PubMed]

35. Tong, W.; Zheng, Q.; Shao, S.; Lei, Q.; Fang, W. Critical Micellar Concentrations of Quaternary Ammonium Surfactants with Hydroxyethyl Substituents on Headgroups Determined by Isothermal Titration Calorimetry. J. Chem. Eng. Data 2010, 55, 37663771. [CrossRef]

36. Majhi, P.R.; Moulik, S.P. Energetics of Micellization: Reassessment by a High-Sensitivity Titration Microcalorimeter. Langmuir 1998, 14, 3986-3990. [CrossRef]

37. Stodghill, S.P.; Smith, A.E.; O'Haver, J.H. Thermodynamics of Micellization and Adsorption of Three Alkyltrimethylammonium Bromides Using Isothermal Titration Calorimetry. Langmuir 2004, 20, 11387-11392. [CrossRef] [PubMed]

38. Bevington, P.R.; Robinson, D.K. Data Reduction and Error Analysis for the Physical Sciences, 3th ed.; Mc. Graw Hill: New York, NY, USA, 2003; Chapter 7; p. 121.

39. Tanford, C. The Hydrophobic Effect: Formation of Micelles and Biological Membranes; John Wiley \& Sons: New York, NY, USA, 1973; Chapter 7; p. 47.

40. Williams, R.J.; Phillips, J.N.; Mysels, K.J. The critical micelle concentration of sodium lauryl sulphate at $25^{\circ} \mathrm{C}$. Trans. Faraday Soc. 1955, 51, 728-737. [CrossRef]

41. Phillips, J.N. The Energetics of Micelle Formation. Trans. Faraday Soc. 1955, 51, 561-569. [CrossRef]

42. Moroi, Y. Micelles: Theoretical and Applied Aspects; Springer Science + Business Media, LLC.: New York, NY, USA, 1992 ; Chapter 4. 
43. Freyer, M.W.; Lewis, E.A. Isothermal titration calorimetry: Experimental design, data analysis, and probing macromolecule/ligand binding and kinetic interactions. Methods Cell Biol. 2008, 84, 79-113.

44. Wiseman, T.; Williston, S.; Brandts, J.F.; Lin, L.-N. Rapid measurement of binding constants and heats of binding using a new titration calorimeter. Anal. Biochem. 1989, 179, 131-137. [CrossRef]

45. Peters, W.B.; Frasca, V.; Brown, R.K. Recent developments in isothermal titration calorimetry label free screening. Comb. Chem. High Throughput Screen. 2009, 12, 772-790. [CrossRef]

46. Biswas, T.; Tsodikov, O.V. An easy-to-use tool for planning and modeling a calorimetric titration. Anal. Biochem. 2010, 406, 91-93. [CrossRef]

47. Broecker, J.; Vargas, C.; Keller, S. Revisiting the optimal c value for isothermal titration calorimetry. Anal. Biochem. 2011, 418, 307-309. [CrossRef] [PubMed]

48. Olesen, N.E.; Westh, P.; Holm, R. Determination of thermodynamic potentials and the aggregation number for micelles with the mass-action model by isothermal titration calorimetry: A case study on bile salts. J. Colloid Interface Sci. 2015, 453, 79-89. [CrossRef] [PubMed] 